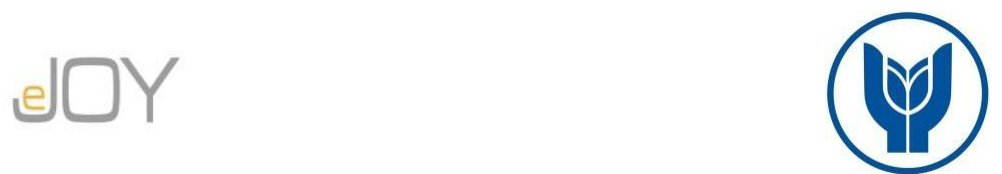

Ateşyakar, N., Duman, E. A. / Journal of Yasar University, 2021, 16/62, 718-738

\title{
Genetics of Risk-Taking Behavior: Current Knowledge, Challenges and Future Directions
}

\section{Risk Alma Davranişinin Genetiği: Güncel Bilgiler, Zorluklar ve Geleceğe Yönelik Öneriler}

\author{
Nilay ATEŞYAKAR, Bogazici University, Turkey, nilay.atesyakar@boun.edu.tr \\ Orcid No: 0000-0002-4540-5445 \\ Elif Aysimi DUMAN, Bogazici University, Turkey, elif.duman@boun.edu.tr \\ Orcid No: 0000-0003-0973-6869
}

\begin{abstract}
Our daily decisions reflect continuous assessments of risk that highly varies from one individual to the other. Research on the underlying mechanisms of individual differences in risk-taking behavior emphasizes changes in neural and physiological pathways that is in part due to the activation of different neurotransmitter systems. Consequently, genetic variations in these systems were the primary target of studies investigating the genetic underpinnings of risk-taking behavior. The aim of this review is to give an overview of our current knowledge related to genetic variations in these systems and economic risk-taking behavior. We first examine candidate gene association studies, followed by genome-wide association and gene-environment interaction studies utilizing different measures of risk-taking to illustrate the progress in the field. Research to date suggests alterations in risk-taking behavior mostly by the genes of serotonergic and dopaminergic systems in addition to influences by psychological trait measures and psychosocial factors. Considering the characteristics and results of these studies, we discuss the limitations and challenges in this area. Finally, we provide suggestions for future genoeconomics research illustrating potential benefits of interdisciplinary studies in behavioral economics.
\end{abstract}

Keywords: Risk-Taking Behavior, Financial Risk-Taking, Genetic Differences, Behavioral Economics, Genoeconomics

\section{JEL Classification: D90, G40, 110}

Öz: Günlük kararlarımız, bir kişiden diğerine oldukça değişen ve süregelen risk değerlendirmelerimizi yansıtır. Risk-alma davranışındaki bireysel farklılıkların altında yatan mekanizmaları araştıran çalışmalar, kısmen farklı nörotransmitter sistemlerinin aktivasyonuyla ilişkili sinirsel ve fizyolojik yolaklardaki değişikliklerin önemini vurgulamaktadır. O nedenle, risk-alma davranışının genetik dayanaklarıyla ilgili araştırmaların öncelikli hedefi, bu sistemlerdeki genetik farklıllklar olmuştur. Bu derlemenin amacı, bu sistemlerdeki genetik farklllıklar ve ekonomik risk-alma davranışı ile ilgili güncel bilgilerimize genel bir bakış sunmaktır. Alandaki gelişimi göstermek için öncelikle farklı risk-alma ölçümleri kullanan aday gen ilişkilendirme çalışmalarının bulguları, sonrasında da genom boyu ilişkilendirme ve gen-çevre etkileşimi çallşmalarının bulguları incelenecektir. Bugüne kadar yapılan araştırmalar, psikolojik özellik ölçümleri ve psikososyal faktörlerin etkilerine ek olarak, çoğunlukla serotonerjik ve dopaminerjik sistem genlerinin risk-alma davranışı üzerindeki etkisini incelemektedir. Bu araştırmaların özellikleri ve sonuçları göz önünde bulundurularak, bu alandaki sınırlamalar ve zorluklar tartışılacaktır. Son olarak, bu bulguların davranışsal ekonomi alanındaki interdisipliner çalışmalar için potansiyel faydaları gösterilerek, gelecekteki genoekonomi araştırmaları için öneriler sunulacaktır.

Anahtar Sözcükler: Risk Alma Davranışı, Finansal Risk Alma, Genetik Farklılıklar, Davranışsal Ekonomi, Genoekonomi

JEL Siniflandirmasi: D90, G40, 110

\section{Introduction}

From our financial decisions to health behaviors, we continuously assess risk in our daily lives by considering potential losses and gains at different domains, and behave accordingly. This risk-taking behavior (RTB) is a major topic of interest in behavioral and experimental economics due to the complex underlying individual differences observed. Recent studies in 
these fields emphasize the importance of attaining an interdisciplinary approach to understanding individual differences in RTB, integrating findings from the fields of psychology, genetics, physiology and neuroscience to provide a more accurate account of how decisions are made under risk (Mishra 2014). The majority of interdisciplinary studies focused on differences in RTB by psychological traits, which possess both genetic and environmental roots (Demaree et al. 2008; Figner and Weber 2011). However, these traits are complex in terms of their neural and physiological representations and may differ across time due to changes in environmental factors, making it challenging to predict RTB. Moreover, given that different RTB paradigms activate different cognitive and emotional processes with different brain circuits and genetic networks involved, understanding differences in RTB through psychological traits becomes difficult (Buelow and Blaine 2015; Stoltenberg and Vandever 2010; Xu et al. 2013). Therefore, recent studies focused on investigating genetic factors separately, referred to as the field of genoeconomics (Benjamin et al. 2012). Authors suggested that this kind of a distinct identification of specific genetic factors would contribute to the field of behavioral economics primarily by identifying the direct contribution of genetic factors which were previously measured as latent parameters (i.e. genetic factor vs. measurement of personality traits that are influenced by these genetic factors). This identification is important, considering the complexity of psychological traits in terms of both genetic and environmental influences. Furthermore, focusing on candidate genetic factors based on the biological pathways they influence may strengthen both the hypotheses formed in relation to economics and identify candidate genetic factors based on previous research in behavioral economics. In addition, considering the importance of correlations and interactions between genetic and environmental factors, considering genetic factors together with environmental factors on economic decisions would allow both identifying their individual effects, as well as their interaction effects. In relation to RTB, there are various studies that consider the influence of different genetic factors on RTB across different domains, such as economic, health, ethical, social, and recreation. While this increase in the number of studies is promising, differences in the domains and measurement of RTB highly varies across these studies, making it challenging to draw conclusions. In this review, we aim to focus primarily on the domain of economic RTB by measures including experimentally elicited economic preferences, self-reports and real-life economic decisions. We provide an overview of the studies focusing on the genetic underpinnings of economic RTB within a structure that reflects different measures of RTB. In this regard, we summarize studies where RTB was conceptualized in terms of financial risk-aversion or risk-seeking (i.e., such as via use of 
BART), risk preferences involving choosing between risky and risk-free assets, loss aversion as measured by Iowa Gambling Task (IGT), gambling paradigms, risk evaluation strategies involving gains and losses and investors' self-reports. We begin by summarizing the biological mechanisms underlying RTB to facilitate the understanding of the selection of candidate genetic factors related to RTB in the next section. Research has documented neural pathways and associated neurotransmitter systems particularly involved in expected value, magnitude, probability of rewards as wells as emotions associated with them. These brain regions and neurotransmitter systems are provided in detail in the following sections. Given that RTB involves sensitivity to reward and influenced by affective processes, it is, thus, highly important to delineate intricate association between RTB and associated neural and molecular mechanisms. We then review later approaches in the field, such as genome-wide association studies (GWAS) and gene-environment interaction (GxE) studies that exemplify the progress in the field. We conclude by discussing the research challenges in the field and suggest directions for future studies.

\section{Biology of Risk-Taking Behavior}

In order to understand the genetics of RTB, it is important to consider research findings on the biology of RTB, which mainly center around alterations in the nervous and neuroendocrine systems related to decision-making. The changes in the structure and function of the nervous system in relation to economic decision-making are mainly driven by the neuroimaging studies in the field of neuroeconomics, facilitating our understanding of neural responses before, during and after risk-taking (Camerer, Loewenstein, and Prelec 2005; Srivastava et al. 2020). These studies emphasize the importance of brain regions such as the ventromedial prefrontal cortex, orbitofrontal cortex, the striatum and posterior parietal cortex in economic RTB, reporting associations with the expected value, probability and magnitude of rewards (Camerer, Loewenstein, and Prelec 2005; Konovalov and Krajbich 2019; Loewenstein, Rick, and Cohen 2008; Srivastava et al. 2020; Zak 2004). Activations in these brain regions are facilitated through the functioning of various neurotransmitters, particularly serotonergic and dopaminergic systems that are involved in emotions, reward processes and executive functioning, influencing our RTB (Daw, Kakade, and Dayan 2002; Heitland et al. 2012; Schultz 2007).

In addition to the nervous system, recent research suggests changes in RTB by the activation of neuroendocrine systems, such as the Hypothalamic-Pituitary-Adrenal (HPA) axis (Coates, Gurnell, and Sarnyai 2010). HPA-axis is one of the major stress response 
systems in the body with the final output of the hormone cortisol from the adrenal cortex. Cortisol release follows a diurnal rhythm reaching the highest levels shortly after awakening with a decline towards the evening. This rhythm is further influenced by exposure to stressors throughout the day, leading to increased cortisol reactivity (Kudielka and Wüst 2010). In the context of RTB, studies report the influence of acute and chronic HPA-axis activation to processes before, during and after RTB (Coates and Herbert 2008; Cueva et al. 2015). For instance, in a preliminary study, researchers found that male traders' cortisol increases as a function of unpredictability of the market and traders' trading outcomes (Coates and Herbert 2008). Another study by Cueva et al. (2015) reported associations between cortisol and RTB during a trading task. Apart from associations, researchers also manipulated cortisol release by administering drugs that mimic cortisol (i.e. hydrocortisone) and showed that the change in drug-induced cortisol levels influence individuals' RTB, shifting their investments to riskier assets. Similarly, Kluen et al. (2017) found that hydrocortisone administration leads to increased RTB as measured by the Balloon Analogue Task (BART) in men only, highlighting the importance of considering sex differences. Similar to the activation of the aforementioned brain regions, activation of the HPA-axis is also influenced by neurotransmitter systems, including serotonin and dopamine, and thus influencing RTB (reviewed in Kreek et al. 2005). For instance, genetic variations in these neurotransmitter systems were shown to alter HPAaxis activity (reviewed in Kudielka and Wüst 2010). In addition, there is evidence for interactions between these systems to further change HPA-axis activation (e.g. Armbruster et al. 2009). Altogether, neural and neuroendocrine changes related to RTB are influenced significantly by the functioning of serotonergic and dopaminergic systems. Consequently, research on individual genetic differences in RTB primarily focuses on genetic variations in these systems, which is reviewed in the next section.

\section{Candidate Genetic Variations and Risk-Taking Behavior}

Earlier research investigating the heritability of RTB in twin study designs has shown moderate heritability utilizing different risk-taking measures ranging from participating in stock markets to taking portfolio risks (Barnea, Cronqvist, and Siegel 2010; Beauchamp, Cesarini, and Johannesson 2017; Cesarini et al. 2009; Cesarini et al. 2010; Nicolaou and Shane 2019; Zyphur et al. 2009). In terms of financial risk preferences, Zyphur et al. (2009) reported a major contribution of genetic factors, explaining $50 \%$ of the variation. Similarly, Cesarini et al. (2009) showed that approximately $20 \%$ of the variation in preferences for risktaking and giving (i.e. as measured by a gambling task and a modified version of the dictator 
game) is explained by genetic factors. In a later study Cesarini et al. (2010) focused on the potential role of genetics on the heterogeneity in portfolio risks, which explained approximately $25 \%$ of the variation. When investor behavior is examined, Barnea, Cronqvist, and Siegel (2010) showed that one-third of variance in stock market participation and asset allocation was attributable to genetic factors. Another study by Beauchamp, Cesarini, and Johannesson (2017) revealed that 35 to $55 \%$ of the variation in risk attitudes was explained by genetic factors. Following these studies, a recent study (Nicolaou and Shane 2019) assessed genetic covariations between different measures of RTB, such as general and domain-specific risk-taking preferences, stock market participation, business formation, and financial investment choices. Findings yielded a common genetic component shared between general and domain-specific risk-taking preferences, together with risk-taking choices. These studies establish the heritability of RTB supporting the importance of investigating related candidate genetic variations. As reviewed above, considering the importance of serotonergic and dopaminergic systems on influencing the biological pathways underlying RTB, majority of these candidate gene studies focused on common genetic variations (genetic polymorphisms) in these systems.

\subsection{Serotonin Transporter}

Serotonin transporter gene (SLC6A4) codes for the serotonin transporter protein that is responsible for the reuptake of excess extracellular serotonin, regulating its availability. A widely studied genetic polymorphism in this gene (i.e. 5-HTTLPR) leads to a Short (S) and a Long (L) variant with differential gene expression levels (Heils et al. 1996). 5-HTTLPR leads to individuals with SS, SL and LL genotypes and was linked to differences in various personality traits (e.g. harm avoidance, neuroticism) and mood disorders (e.g. depression, anxiety), together with its interaction with stressful life events (Caspi et al. 2010; Duman 2018). In relation to RTB, several studies utilized experimentally elicited economic preferences to assess differences between individuals with $\mathrm{S}$ and $\mathrm{L}$ variants. For example, when individuals were asked to make investment decisions and allocate funds between risky and risk-free assets, SS individuals were more risk averse than L-carriers (Kuhnen and Chiao 2009). Similarly, He et al. (2010) revealed that Asians with the SS genotype, particularly males, chose more disadvantageous cards on IGT with immediate gains but higher future losses, as well as exhibited higher loss aversion compared to L-carriers. In line with these studies, S-carriers were reported to be more risk averse compared to LL individuals, as measured by BART (Crişan et al. 2009). The same trend was also observed in response to 
self-reported RTB (i.e. DOSPERT scale; Crişan et al. 2009). In contrast to He et al.'s study, Stoltenberg et al. (2011) reported that Caucasian S-carriers engaged in more advantageous choices on IGT under ambiguity, compared to LL individuals. The potential reasons behind this discrepancy might be the differences in the IGT design (the blocks considered), frequency of 5-HTTLPR variants among Asian and European populations, ethnicity/culture, and grouping of genotypes (i.e. S-carries vs. LL and SS vs. L-carriers). When they analyzed the blocks of IGT similar to He et al., they reported a resemblance in results, but the effects were nonsignificant. Considering the findings of these studies, Caucasian S-carriers are mostly reported to have lower RTB.

In addition to studies examining engagement in RTB, Roiser et al. (2006; 2009) assessed potential genotypic difference in risk evaluation strategies. Roiser et al. (2006) showed that during a risky decision-making task, S-carriers paid higher attention to the variance in the probability of winning the selected gambles than LL individuals. This study was followed by an investigation of the role of 5-HTTLPR in response to framing (Roiser et al. 2009). Utilizing a monetary forced choice task in which participants choose between a certain option and a gamble, they found SS individuals to be more vulnerable to the framing than LL individuals. Specifically, they preferred the certain option when it was shown as gains, and the gamble, when it was shown as losses. These results further provided support for sensitivity of Scarriers to RTB. More recently, Millroth et al. (2017) sought to answer whether this sensitivity is due to uncertainty or magnitude of the outcomes. They utilized a willingness to pay task involving prospects with certain, uncertain and ambiguous gain. The results revealed that S-carriers were willing to pay more for all prospects in comparison to LL individuals, suggesting S-carriers to be more reactive to the magnitude of the outcome rather than its uncertainty (Millroth et al. 2017). As opposed to all these studies reporting a significant effect of 5-HTTLPR on RTB, others failed to find a link when RTB was measured as monetary gambles (Frydman et al. 2011), investors' self-report or real economic choices (Anderson, Dreber, and Vestman 2015) or multiple price list designs (Zhong et al. 2009a).

Research has further documented the potential role of psychological traits in the relationship between 5-HTTLPR and RTB. A study on real life economic preferences indicated that S-carriers were less likely to engage in complex and risky financial choices than LL individuals. Furthermore, this association was mediated by S-carriers' increased neuroticism (Kuhnen, Samanez-Larkin, and Knutson 2013). Researchers therefore suggested that these individuals may refrain from risky financial choices because of the negative emotional reactions and increased anxiety elicited by risky outcomes. In line with this finding, 
female S-carriers were reported to follow a cautious strategy by showing decreased risktaking following gains in a gambling task, supporting the link between the $S$ variant, harm avoidance and neuroticism (Heitland et al. 2012). These results emphasize the importance of considering psychological traits as possible mediators between genetic factors and RTB. Ernst et al. (2014) investigated the role of anxiety and 5-HTTLPR variation in the modulation of loss aversion. Adolescents diagnosed with anxiety and controls did not differ in terms of loss aversion. Also, 5-HTTLPR variation did not influence loss aversion in adolescents with no anxiety disorder. However, they found highly anxious LL individuals to have significantly lower risk aversion and higher impulsivity. On the contrary, Stamatis et al. (2020) reported SS individuals with higher social anxiety to exhibit increased risk-seeking. The discrepancy between these findings might be due to the anxiety measures utilized. Whereas anxious group in Ernst et al. (2014) consisted of individuals with a variety of anxiety disorders, Stamatis et al. (2020) focused specifically on social anxiety disorder which is marked by both risk avoidance and reactive risk-seeking, such as alcohol and substance use. Furthermore, Ernst et al. (2014) had a small sample size, which may have resulted in failure to find higher loss aversion in anxious S-carriers compared to healthy individuals, as authors claimed. In comparison to studies associating S-variant with increased risk and loss aversion, Neukam et al. (2018) only found that SS individuals were more risk-seeking for losses than L-carriers. However, for instance, whereas (Kuhnen, Samanez-Larkin, and Knutson 2013) utilized an investment task, Neukam et al. (2018) assessed the choice participants were likely to prefer when presented with sure and probabilistic gains. Yet, different measures of economic preferences involve different decision making and emotional processes (Buelow and Blaine 2015; $\mathrm{Xu}$ et al. 2013) and thus different brain circuits with different genetic make-up and neurotransmitter systems (Brand, Labudda, and Markowitsch 2006; Stoltenberg and Vandever 2010). In addition to the differences in the tasks, previous research suggests the importance of demographic factors, such as age and sex. For instance, whereas Neukam et al. (2018) used a community sample, He et al. (2010) studied with young college students, which may influence RTB depending on task characteristics (Mata et al. 2011). There are also differences between studies in terms of participants' sex. For example, Heitland et al. (2012) only recruited female subjects, which may influence serotonergic and dopaminergic systems differently compared to males, through estrogen (He et al. 2010; Heitland et al. 2012). Considering these studies related to 5-HTTLPR and RTB, there is evidence for the effect of genotype on RTB across multiple measures. However, the variability in participant 
characteristics (e.g. demographics, psychological traits), differences in RTB measures and genotype grouping makes it difficult to draw firm conclusions from existing research.

\subsection{Dopamine Transporter}

Dopamine transporter gene $(D A T 1)$ is responsible for producing the dopamine transporter protein that is involved in the reuptake of excess extracellular dopamine, regulating the dopaminergic tone. A commonly investigated genetic polymorphism in this gene leads to different numbers of repeats of a region in the gene, leading to individuals with 3 to 13 repeats with varying $D A T 1$ gene expression. The most frequently found variants are 9 and 10 repeats (Sano et al. 1993). Individuals carrying the 9-repeat variation express dopamine transporter less, leading to an increased amount of dopamine in reward-related areas, although conflicting results exist (Heinz et al. 2000; Jacobsen et al. 2000; Martinez et al. 2001). In relation to RTB measured by BART, 9-repeat carriers were associated with differences in risk-taking and cognitive control (Mata et al. 2012), exhibiting less RTB compared to 10 and 11-repeat carriers. In contrast, Heitland et al. (2012) reported that in a sample of European female college students, 9-repeat carriers showed differential prefrontal brain responses and increased RTB following losses during an experimental gambling paradigm. Interestingly, Zhong et al. (2009a) reported in Asians that DATl polymorphism is only linked to risk attitude over gains, but not losses. Specifically, they found that compared to 10-repeat carriers, 9-repeat carriers are more risk-tolerant over gains. Similar to findings on 5-HTTLPR in relation to RTB, here again, the discrepancy between the studies might be attributable to the characteristics of the participants in the studies and also use of different RTB measures. For instance, whereas Zhong et al. (2009a) conducted the experiment with Asian population, Heitland et al. (2012) recruited an European sample. Furthermore, for example, the sample in Mata et al. (2012) consisted of adults from age of eighteen to fifty, yet Heitland et al. (2012) only used a small sample of female college students. With regard to RTB measures, whereas Heitland et al. (2012) used an gambling task, Zhong et al. (2009a) utilized a multiple price list design and Mata et al. (2012) only used BART. Altogether these results highlight the need for further studies, which may allow for more detailed analyses of the literature and lead to more consistent findings.

\subsection{Dopamine Receptor 4}

Dopamine receptor 4 gene (DRD4) encodes the D4 type of the dopamine receptor that binds dopamine. The commonly investigated genetic polymorphism in this gene leads to individuals with different numbers of repeats, ranging from 2 to 11 repeats (Ding et al. 2002). The 7- 
repeat variant was previously associated with a blunted dopamine response and suggested to contribute to differences in dopamine-related psychological traits, behaviors and disorders, such as novelty-seeking, impulsivity, attention deficit hyperactivity disorder, and behavioral disinhibition (Congdon, Lesch, and Canli 2008; Eisenberg et al. 2007; Li et al. 2006; Munafò et al. 2008). In relation to RTB, while some studies failed to find a significant effect (Anderson, Dreber, and Vestman 2015; Dreber et al. 2012; Eisenegger et al. 2010; Frydman et al. 2011; Muda et al. 2018; Sapra, Beavin, and Zak 2012; Wernerfelt et al. 2012), most of the studies reported increased RTB in 7-repeat carriers. For instance, in an investment game with real monetary payoffs, Dreber et al. (2009) reported higher RTB in male 7-repeat carriers compared to others. Similarly, 7-repeat carriers were found to engage in higher RTB by $25 \%$ than others when asked to make investment decisions (Kuhnen and Chiao 2009). Likewise, in a sample of bridge tournament players, Dreber et al. (2011a) showed that male 7-repeat carriers take higher risks in an investment game than others. However, self-report measures revealed no dissociation between the two groups in terms of both general risk-taking and riskrelated activities engaged. With the same group of participants (Dreber et al. 2011b), the researchers again failed to find a link between $D R D 4$ polymorphism and self-reported risk taking in multiple economic decision-making domains. Authors claimed that the absence of the effect in self-reports of risky behavior may be attributed to the lack of self-awareness of 7repeats carriers. Carpenter, Garcia, and Lum (2011) reported that 7-repeat carriers are not particularly risk-seeking compared to 4-repeat carriers. However, in cases of ambiguous probabilities and possibilities of losses, they select options (i.e. lotteries) with higher risk, which may support Dreber et al.'s perspective (2011b). Through a self-report survey measuring real life choices, they further reported 7-repeat individuals to hold fewer funds in savings, use debit cards rather than credit cards, and less likely to pay their monthly credit card balance. Among the studies that reported no significant associations, Eisenegger et al. (2010) interestingly reported higher gambling propensity in 7-repeat carriers compared to non-carriers, but only after administration of a dopaminergic drug (L-dihydroxyphenyalanine; L-DOPA), suggesting that the type and timing of RTB may also influence the results.

\subsection{Catechol-O-Methyltransferase}

Catechol-O-methyltransferase gene (COMT) codes for the COMT enzyme that catalyzes the degradation of catecholamines like dopamine. A polymorphism in this gene leads to an enzyme with Valine (Val) or Methionine (Met) amino acid. The Met variant of the enzyme shows 3 to 4 times less enzymatic activity than the Val variant and is associated with 
differences in executive function, reward, and alcoholism (Lancaster, Linden, and Heerey 2012; Mier, Kirsch, and Meyer-Lindenberg 2010; Kreek et al. 2005). Only a few studies were conducted in relation to RTB. In one study, Met/Met individuals were reported to exhibit higher reward-seeking and -responsiveness (Lancaster, Linden, and Heerey 2012). Similarly, Met-carrier females, but not males, scored significantly higher in the youth version of BART, indicating a higher risk-taking propensity compared to Val/Val females (Amstadter et al. 2012). Supporting these studies, in a study with females, compared to Val-carriers, Met/Met individuals showed a gradual increase in RTB as the duration of a gambling task was extended (Heitland et al. 2012). These results suggest that the COMT Met variant may be associated with increased RTB, particularly in females.

\subsection{Monoamine Oxidase A}

Monoamine oxidase A gene (MAOA) codes for the MAOA enzyme that catalyzes the breakup of monoamines, including serotonin and dopamine. The gene has a polymorphism that leads to variants with different numbers of repeats, altering gene expression levels (Sabol, Hu, and Hamer 1998). Carriers of the 3.5 or 4 repeat variants display higher expression of the enzyme (MAOA-High; MAOA-H) in comparison to carriers of the 2, 3 or 5 repeat variants with lower expression (MAOA-Low; MAOA-L). Many studies associated individuals with the MAOA-L variants with impulsivity, aggression and violence (Caspi et al. 2002; McDermott et al. 2009). In relation to $\mathrm{RTB}$, there are conflicting results with studies utilizing a wide range of risktaking measurements, rendering comparisons between studies challenging. For instance, Frydman et al. (2011) reported that MAOA-L carriers engaged in higher financial RTB than MAOA-H carriers, but only during advantageous gambles in a sample of male participants. Interestingly, through a computational choice model, researchers revealed that the results are not due to the impulsivity of MAOA-L carriers, but to their ability to make better financial decisions under risk. Similarly, MAOA-L carriers was linked to increased RTB as revealed by higher credit card debt in young adults (De Neve and Fowler 2014). In contrast, Zhong et al. (2009b) showed that MAOA-H individuals exhibit higher RTB compared to those MAOA-L individuals, as indicated by a higher preference to longshot lottery and a lower preference to investing in insurance purchases.

Apart from these findings, studies conducted with people with increased exposure to risky situations failed to find effect of MAOA genotype on RTB. For instance, Dreber et al. (2012) investigated RTB in professionals with high socioeconomic status (SES) and successful experiences in starting multiple companies and found no variation by MAOA genotype in financial RTB. Similarly, in highly accomplished managers, Wernerfelt et al. (2012) could not 
find effect of MAOA genotype on entrepreneurial activity as measured by number of companies founded. These findings suggest that the influence of MAOA genotype may differ depending on sex, the risk-taking task utilized and the experience of participants with risky circumstances.

The candidate gene studies related to RTB, particularly pertaining to the serotonergic and dopaminergic systems, are important in identifying genetic factors related to the decisionmaking processes under risk. However, investigating the effect of single genes without the influence of others is limited to explaining only a small portion of the variation in RTB. In order to explain more of the variance, some researchers conducted polymorphisms across the genome (Genome-Wide Association Studies; GWAS), which will be discussed next.

\section{Genome-Wide Association Studies and Risk-Taking Behavior}

GWAS is a commonly utilized method for identifying genetic polymorphisms across the genome that are observed more frequently in a group of individuals compared to others (Bush and Moore 2012; Hirschhorn and Daly 2005). Most of the time the groups are formed by people at the opposite extremes of a behavior or those with or without a disorder. By analyzing the frequencies of several hundred thousand genetic polymorphisms between these groups, researchers are able to find genetic polymorphisms that are more frequently observed in one group compared to the other. In relation to RTB, an earlier GWAS comparing quartiles of elderly in terms of risk aversion to hypothetical gambles failed to identify any polymorphisms that was different between the groups beyond the significance level (Harrati 2014). On the other hand, later GWAS studies with self-reports of RTB identified multiple genetic polymorphisms that pass the significance threshold. For instance, utilizing over four hundred thousand individuals' samples from European UK Biobank study, Clifton et al. (2018) identified 26 genetic loci linked to self-reported categorization of oneself as a risktaker or not. The polymorphisms identified were mostly related to the pathways of the inhibitory neurotransmitter GABA. More importantly, they further showed significant genetic correlations between risk-taking and multiple variables related to smoking, metabolism and different psychological disorders, suggesting the influence of these polymorphisms on common biological systems. Comparison of the same groups (risk-taker or not) in another study with more than one thousand individuals from the same biobank, Strawbridge et al. (2018) identified 2 genetic loci associated with self-reported RTB. In line with Clifton et al. (2018)'s findings, they also reported genetic correlations between RTB and smoking, metabolism and multiple psychological disorders. More recently, Linnér et al. (2019) 
conducted a GWAS with more than a million participants from Europe and US to find genetic variations related to RTB. In addition to the self-report general RTB measure mentioned above, they included risk measures from different cohorts related to being adventurous and exhibiting risky behaviors related to smoking, drinking, sex, and driving. Findings revealed 99 genetic loci attributable to general risk tolerance with shared genetic influences between increased general risk tolerance and risky behavior, some of which further overlapped with previous GWAS findings on RTB. These loci were primarily related to the functioning of glutamate and GABA neurotransmitter systems. Furthermore, researchers reported a substantial influence of demographic and environmental factors, such as age, sex, and life events, emphasizing the importance of considering environmental factors together with genetic factors. The results of these GWAS are powerful in terms of understanding the gene networks associated with RTB and behaviors/disorders that are influenced by shared genetic variations. However, due to population heterogeneity, it is difficult to replicate the findings across multiple studies. Moreover, as shown by Linnér et al., the contribution of environmental factors is always in effect to moderate the influence of genetic factors. In the next section, we therefore review the limited number of studies that investigated both the genetic and environmental factors and their interaction $(\mathrm{GxE})$ to understand differences in RTB.

\section{Gene-Environment Interaction Studies and Risk-Taking Behavior}

While research on psychological disorders have attained the perspective of investigating the mutual contribution of genetic and environmental factors for the last two decades (Duman, 2018), research on economic RTB is limited in terms of GxE studies. Considering previous research, several demographic and environmental factors have been associated with differential RTB, such as age, SES, and exposure to stressful life events (Ceccato, Kudielka, and Schwieren 2016; Felsher, Derevensky, and Gupta 2010; Grable 2000; Nicholson et al. 2005; Senn and Carey 2010; Zuckerman and Kuhlman 2000). For instance, after developing a scale to assess individual differences in RTB across domains, Wang et al. (2016) conducted a twin study and later combined their findings with previous twin studies in a meta-analysis. Their results revealed that individual variances in risk-taking tendency is mostly attributable to additive genetic and non-shared environmental factors, including personally unique experiences. Another study investigated the interaction between 5-HTTLPR and childhood maltreatment on RTB as measured by performance during IGT in young adults. Compared to individuals with low childhood maltreatment, those with higher childhood maltreatment 
engaged in worse decision-making performance under risk. Furthermore, childhood trauma was not found to interact with 5-HTTLPR to influence decision-making under ambiguity or risk. However, LL individuals were found to engage in riskier decision-making by choosing more cards from "bad" decks under ambiguity, but not risk in IGT, compared to S-carriers (Stoltenberg et al. 2011). Similarly, as a measure of early life environment, Sweitzer et al. (2013) investigated the contribution of childhood SES on delay discounting as a function of DRD4 genotype in middle-aged community volunteers. Results revealed that among individuals with low childhood SES, 7-repeat carriers exhibited higher discounting of future rewards compared to 7-repeat non-carriers, controlling for sex, age, IQ and adulthood SES. On the contrary, an opposite pattern was observed among those with high childhood SES, such that 7-repeat carriers discounted future rewards less sharply compared to 7-repeat noncarriers. Altogether, these findings highlight the importance of considering the influence of environmental factors on the relationship between genetic variations and RTB.

\section{Challenges and Future Directions}

Genoeconomics research, at the intersection of economics and genetics, has been gathering attention in the past decades following its contributions to long-lasting economic theories of human behavior explaining economic decision-making processes (Benjamin et al. 2012; Lakshmanasamy 2014; Lehrer and Ding 2017). Previous attempts to delineate the potential genetic mechanisms underlying economic RTB found its route in heritability studies. Findings revealed that economic risk-taking indeed has a varying degree of heritability. Candidate gene studies related mainly to serotonergic and dopaminergic neurotransmitter systems introduced new avenues of research to understand how individual genetic polymorphisms can contribute to variances in RTB. In parallel, GWAS gained attention to assess genome-wide assessments of genetic variations in larger populations, which revealed some genetic variations associated with self-reported risk-taking, particularly related to glutamergic and GABAergic neurotransmitter systems. Recently, GxE studies highlighted the importance of considering environmental factors while assessing the genetic underpinnings of economic RTB.

Despite the increase in the number of studies, accumulating amount of research led to equivocal findings due to existing challenges in the field. One major challenge is the use of different measures of economic RTB that ranges from self-reports to experimental and reallife paradigms with different incentives. Considering that different economic preference tasks would have different characteristics of risk (e.g. ambiguity, probability), they may be associated with different neurotransmitter systems and neural and physiological activation 
patterns related to decision-making processes. Hence, opposing findings in the genoeconomics literature may be attributed to the use of a wide range of RTB paradigms. Future studies therefore may benefit from both replication studies with previously published measures as well as studies with multiple measures of RTB. Moreover, considering the use of neural endophenotypes in explaining larger portion of variance in behavior, compared to selfreport and behavioral measures, utilizing neural and physiological measures of RTB would enhance our understanding of individual differences in RTB.

Another challenge in the field is with respect to the genetic polymorphisms considered related to RTB. In the context of candidate gene studies, categorization of genotype groups is frequently arbitrary, making it difficult to compare groups across studies. In addition, since single genetic polymorphisms explain a minor portion of the variance in RTB and that RTB is influenced by multiple neurotransmitter systems, considering only single genetic polymorphisms is a limitation. While, this limitation is partially addressed by GWAS that provided important insights, these studies are constrained in the depth of the measurement of risk and comparisons between studies as they require large sample sizes often driven from international biobanks (Torkamani, Topol, and Schork 2008; Kraft, Zeggini, and Ioannidis 2009; Marigorta et al. 2018). In this respect, replication studies are critical, as exemplified by GWAS studies emphasizing the GABAergic influences on risk-taking, together with a more detailed measurement of risk. Finally, despite the rise of GxE studies in psychology, the moderating role of environmental factors on the genetics of RTB is rarely considered in the field. Despite previous research suggesting changes in RTB by age, sex, SES, personality, exposure to risk and stressful life events, childhood maltreatment and social relationships (Ceccato, Kudielka, and Schwieren 2016; Felsher, Derevensky, and Gupta 2010; Grable 2000; Nicholson et al. 2005; Senn and Carey 2010; Telzer et al. 2015; Zuckerman and Kuhlman 2000), these factors were examined in a very small number of genoeconomics studies. In addition to the limited amount of research, these studies mostly focused on one psychosocial or environmental variable (e.g., only measuring anxiety). Nevertheless, only one psychosocial variable or an environmental factor rarely account for a behavioral outcome. They rather interact with each other to influence behavior. For example, positive factors, such as increased social support and optimism, may protect against the adverse effects of childhood trauma. Therefore, considering only childhood trauma as an environmental factor in an RTB study might be misleading. Furthermore, different genetic polymorphisms with different neurotransmitter systems associated with them are likely to interact with different environmental and psychosocial factors. Hence, it would be highly beneficial for future 
studies to investigate multiple genetic polymorphisms together with potential environmental factors to explain differences in economic RTB.

In order to understand individual differences in economic RTB while addressing the aforementioned challenges, we initiated an interdisciplinary project between economics and psychology departments that investigates (1) GxEs related to RTB, by focusing on psychosocial factors (e.g. life events, SES) and four commonly investigated genetic polymorphisms of the serotonergic and dopaminergic systems, (2) the role of physiological responses (i.e. HPA-axis stress reactivity under risk) as an endophenotype, and (3) the comparison of these findings across different economic risk-taking measures in young adults. Through this project, we aim to advance our understanding of the individual differences and underlying mechanisms pertaining to RTB, contributing to studies in behavioral economics. In this way, it would be possible to better predict individuals at a higher risk for certain disruptive behaviors and disorders (e.g. gambling, addictions, violence) and develop targeted prevention and intervention strategies (Kreek et al. 2005). Empirical economists may benefit from molecular genetic data in their assessment of causal effects (Beauchamp et al. 2011). Genetic factors may be taken as covariates and increase power of economic analyses (Benjamin et al. 2012). Furthermore, genetic markers underlying economic behavior, health and socioeconomic outcomes as well as its interaction with psychosocial and environmental factors can help policymakers personalize the way policies are delivered to people, such as personalized medicine (Lehrer and Ding 2019).

\section{Conclusion}

Considering the findings of candidate gene, GWAS and GxE studies, there is strong evidence for the importance of genetic factors on individual differences in RTB. While there are limitations in research in all of these areas, with increasing number of studies utilizing similar RTB measurements, the field is moving towards more consistent effects of genetic factors on RTB. For instance, 5-HTTLPR, as a widely studied genetic polymorphism in the field, sets a good example for the way the knowledge should be broadened to achieve more consistent effects. Initial research mostly yielded that SS individuals are more likely to be risk-averse compared to L-carriers. However, later studies with different populations (i.e. Asian vs European), different demographic groups, and with various RTB tasks showed the multifaceted nature of RTB. On the top of this, GxE studies on the association between 5HTTLPR and RTB documented the necessity of adopting psychological trait measures, such as personality and anxiety. Furthermore, additional studies emphasized the importance of 
other psychosocial factors, such as early life environment. Research on mood disorders and related molecular, neural and physiological endophenotypes indeed revealed that it is not genes or environment per se, but the interaction between them that influences vulnerability to complex behaviors and disorders (Duman 2018). Therefore, while examining RTB, it is important for genoeconomics research to include to environmental factors together with genetic factors. Through these additions, individual differences in economic RTB may be better understood, which would have reflections in various fields, including finance, psychology, and health. 


\section{REFERENCES}

Amstadter, Ananda B., Laura MacPherson, Frances Wang, Annie Banducci, Elizabeth K. Reynolds, Marc N. Potenza, Joel Gelernter, and C. W. Lejuez. 2012. "The Relationship between Risk-Taking Propensity and the COMT Val158Met Polymorphism among Early Adolescents as a Function of Sex." Journal of Psychiatric Research 46 (7): 940-45. https://doi.org/10.1038/jid.2014.371.

Anderson, Anders, Anna Dreber, and Roine Vestman. 2015. "Risk Taking, Behavioral Biases and Genes: Results from 149 Active Investors." Journal of Behavioral and Experimental Finance 6: 93-100. https://doi.org/10.1016/j.jbef.2015.04.002.

Armbruster, D., A. Mueller, D. A. Moser, K. P. Lesch, B. Brocke, and C. Kirschbaum. 2009. "Interaction Effect of D4 Dopamine Receptor Gene and Serotonin Transporter Promoter Polymorphism on the Cortisol Stress Response.” Behavioral Neuroscience 123 (6): 1288-95. https://doi.org/10.1037/a0017615.

Barnea, Amir, Henrik Cronqvist, and Stephan Siegel. 2010. "Nature or Nurture: What Determines Investor Behavior?" Journal of Financial Economics $98 \quad$ (3): $583-604$. https://doi.org/10.1016/j.jfineco.2010.08.001.

Beauchamp, Jonathan P., David Cesarini, and Magnus Johannesson. 2017. "The Psychometric and Empirical Properties of Measures of Risk Preferences." Journal of Risk and Uncertainty 54 (3): 203-37. https://doi.org/10.1007/s11166-017-9261-3.

Beauchamp, Jonathan P., David Cesarini, Magnus Johannesson, Matthijsj H.M. Van Der Loos, Philipp D. Koellinger, J. F.Groenen Patrick, James H. Fowler, J. Niels Rosenquist, A. Roy Thurik, and Nicholas A. Christakis. 2011. "Molecular Genetics and Economics." Journal of Economic Perspectives 25 (4): 5782. https://doi.org/10.1257/jep.25.4.57.

Benjamin, Daniel J., David Cesarini, Christopher F. Chabris, Edward L. Glaeser, David I. Laibson, Vilmundur Gunason, Tamara B. Harris, et al. 2012. "The Promises and Pitfalls of Genoeconomics." Annual Review of Economics 4: 627-62. https://doi.org/10.1146/annurev-economics-080511-110939.

Brand, Matthias, Kirsten Labudda, and Hans J. Markowitsch. 2006. "Neuropsychological Correlates of Decision-Making in Ambiguous and Risky Situations." Neural Networks 19 (8): 1266-76. https://doi.org/10.1016/j.neunet.2006.03.001.

Buelow, Melissa T., and Amber L. Blaine. 2015. "The Assessment of Risky Decision Making: A Factor Analysis of Performance on the Iowa Gambling Task, Balloon Analogue Risk Task, and Columbia Card Task." Psychological Assessment 27 (3): 777-85.

Bush, William S., and Jason H. Moore. 2012. "Chapter 11: Genome-Wide Association Studies." PLoS Computational Biology 8 (12). https://doi.org/10.1371/journal.pcbi.1002822.

Camerer, Colin, George Loewenstein, and Drazen Prelec. 2005. "Neuroeconomics: How Neuroscience Can Inform Economics." Journal of Economic Literature $43 \quad$ (1): 9-64. https://doi.org/10.1257/0022051053737843.

Carpenter, Jeffrey P., Justin R. Garcia, and J. Koji Lum. 2011. "Dopamine Receptor Genes Predict Risk Preferences, Time Preferences, and Related Economic Choices." Journal of Risk and Uncertainty 42 (3): 233-61. https://doi.org/10.1007/s11166-011-9115-3.

Caspi, Avshalom, Ahmad R. Hariri, A Holmes, R Uher, and Terrie E. Moffitt. 2010. "Genetic Sensitivity to the Environment: The Case of the Serotonin Transporter Gene and Its Implications for Studying Complex Diseases and Traits." American Journal of Psychiatry 167: 509-27. https://doi.org/10.1176/appi.ajp.2010.09101452.

Caspi, Avshalom, Joseph McCray, Terrie E. Moffitt, Jonathan Mill, Judy Martin, Ian W. Craig, Alan Taylor, and Richie Poulton. 2002. "Role of Genotype in the Cycle of Violence in Maltreated Children." Science 297 (5582): 851-54. https://doi.org/10.1126/science.1072290.

Ceccato, Smarandita, Brigitte M. Kudielka, and Christiane Schwieren. 2016. "Increased Risk Taking in Relation to Chronic Stress in Adults." Frontiers in Psychology 6: 2036. https://doi.org/10.3389/fpsyg.2015.02036.

Cesarini, David, Christopher T. Dawes, Magnus Johannesson, Paul Lichtenstein, and Björn Wallace. 2009. "Genetic Variation in Preferences for Giving and Risk Taking." Quarterly Journal of Economics 124 (2): 809-42. https://doi.org/10.1162/qjec.2009.124.2.809.

Cesarini, David, Magnus Johannesson, Paul Lichtenstein, Örjan Sandewall, and Björn Wallace. 2010. "Genetic Variation in Financial Decision-Making." Journal of Finance 65 (5): 1725-54. https://doi.org/10.1111/j.1540-6261.2010.01592.x.

Clifton, Emma A.D., John R.B. Perry, Fumiaki Imamura, Luca A. Lotta, Soren Brage, Nita G. Forouhi, Simon J. Griffin, Nicholas J. Wareham, Ken K. Ong, and Felix R. Day. 2018. "Genome-Wide Association Study for Risk Taking Propensity Indicates Shared Pathways with Body Mass Index." Communications Biology 1 (1). https://doi.org/10.1038/s42003-018-0042-6.

Coates, John M., Mark Gurnell, and Zoltan Sarnyai. 2010. "From Molecule to Market: Steroid Hormones and Financial Risk-Taking.” Philosophical Transactions of the Royal Society B: Biological Sciences 365 
(1538): 331-43. https://doi.org/10.1098/rstb.2009.0193.

Coates, John M, and Joe Herbert. 2008. "Endogenous Steroids and Financial Risk Taking on a London Trading Floor." Proceedings of the National Academy of Sciences 105 (16): 6167-72. https://doi.org/10.1073/pnas.0704025105.

Congdon, Eliza, Klaus Peter Lesch, and Turhan Canli. 2008. "Analysis of DRD4 and DAT Polymorphisms and Behavioral Inhibition in Healthy Adults: Implications for Impulsivity." American Journal of Medical Genetics, Part B: Neuropsychiatric Genetics 147 (1): 27-32. https://doi.org/10.1002/ajmg.b.30557.

Crişan, Liviu G., Simona Pană, Romana Vulturar, Renata M. Heilman, Raluca Szekely, Bogdan Drugă, Nicolae Dragoş, and Andrei C. Miu. 2009. "Genetic Contributions of the Serotonin Transporter to Social Learning of Fear and Economic Decision Making." Social Cognitive and Affective Neuroscience 4 (4): 399-408. https://doi.org/10.1093/scan/nsp019.

Cueva, Carlos, R. Edward Roberts, Tom Spencer, Nisha Rani, Michelle Tempest, Philippe N. Tobler, Joe Herbert, and Aldo Rustichini. 2015. "Cortisol and Testosterone Increase Financial Risk Taking and May Destabilize Markets.” Scientific Reports 5 (1): 1-16. https://doi.org/10.1038/srep11206.

Daw, Nathaniel D., Sham Kakade, and Peter Dayan. 2002. "Opponent Interactions between Serotonin and Dopamine.” Neural Networks 15 (4-6): 603-16. https://doi.org/10.1016/S0893-6080(02)00052-7.

Demaree, Heath A., Michael A. DeDonno, Kevin J. Burns, and D. Erik Everhart. 2008. "You Bet: How Personality Differences Affect Risk-Taking Preferences." Personality and Individual Differences 44 (7): 1484-94. https://doi.org/10.1016/j.paid.2008.01.005.

Ding, Yuan Chun, Han Chang Chi, Deborah L. Grady, Atsuyuki Morishima, Judith R. Kidd, Kenneth K. Kidd, Pamela Flodman, et al. 2002. "Evidence of Positive Selection Acting at the Human Dopamine Receptor D4 Gene Locus." Proceedings of the National Academy of Sciences 99 (1): 309-14. https://doi.org/10.1073/pnas.012464099.

Dreber, A., D. G. Rand, N. Wernerfelt, J. R. Garcia, M. G. Vilar, J. K. Lum, and R. Zeckhauser. 2011. "Dopamine and Risk Choices in Different Domains: Findings among Serious Tournament Bridge Players." Journal of Risk and Uncertainty 43 (1): 19-38. https://doi.org/10.1007/s1 1166-011-9119-z.

Dreber, Anna, Coren L. Apicella, Dan T.A. Eisenberg, Justin R. Garcia, Richard S. Zamore, J. Koji Lum, and Benjamin Campbell. 2009. "The 7R Polymorphism in the Dopamine Receptor D4 Gene (DRD4) Is Associated with Financial Risk Taking in Men.” Evolution and Human Behavior 30 (2): 85-92. https://doi.org/10.1016/j.evolhumbehav.2008.11.001.

Dreber, Anna, David G. Rand, Nils Wernerfelt, Justin R Garcia, J Koji Lum, and Richard Zeckhauser. 2011. "The Dopamine Receptor D4 Gene (DRD4) and Self-Reported Risk Taking in the Economic Domain." HKS Faculty Research Working Paper Series, John F. Kennedy School for Government, Harvard University.

Dreber, Anna, David G. Rand, Nils Wernerfelt, Cynthia Montgomery, and Deepak K. Malhotra. 2012. "Dreber, A., Rand, D. G., Wernerfelt, N., Montgomery, C., \& Malhotra, D. K. (2012). Genetic Correlates of Economic and Social Risk Taking." Available at SSRN 2141601. https://doi.org/10.2139/ssrn.2141601.

Duman, Elif Aysimi. 2018. "Stress and Psychosomatic Disorders: Importance of Gene-Environment Interactions and Epigenetic Mechanisms." Turkey Clinics Psychiatry 11 (2): 6-15.

Eisenberg, Dan T.A., James MacKillop, Meera Modi, Joshua Beauchemin, David Dang, Stephen A. Lisman, J. Koji Lum, and David S. Wilson. 2007. "Examining Impulsivity as an Endophenotype Using a Behavioral Approach: A DRD2 TaqI A and DRD4 48-Bp VNTR Association Study." Behavioral and Brain Functions 3: 1-14. https://doi.org/10.1186/1744-9081-3-2.

Eisenegger, Christoph, Daria Knoch, Richard P. Ebstein, Lorena R.R. Gianotti, Peter S. Sándor, and Ernst Fehr. 2010. "Dopamine Receptor D4 Polymorphism Predicts the Effect of L-DOPA on Gambling Behavior." Biological Psychiatry 67 (8): 702-6. https://doi.org/10.1016/j.biopsych.2009.09.021.

Ernst, Monique, Rista C. Plate, Christina O. Carlisi, Elena Gorodetsky, David Goldman, and Daniel S. Pine. 2014. "Loss Aversion and 5HTT Gene Variants in Adolescent Anxiety." Developmental Cognitive Neuroscience 8: 77-85. https://doi.org/10.1016/j.dcn.2013.10.002.

Felsher, Jennifer R., Jeffrey L. Derevensky, and Rina Gupta. 2010. "Young Adults with Gambling Problems: The Impact of Childhood Maltreatment." International Journal of Mental Health and Addiction 8 (4): 545-56. https://doi.org/10.1007/s11469-009-9230-4.

Figner, Bernd, and Elke U. Weber. 2011. "Who Takes Risks When and Why? Determinants of Risk Taking." Current Directions in Psychological Science $20 \quad$ (4): $211-16$. https://doi.org/10.1177/0963721411415790.

Frydman, Cary, Colin Camerer, Peter Bossaerts, and Antonio Rangel. 2011. "MAOA-L Carriers Are Better at Makingoptimal Financial Decisions under Risk." Proceedings of the Royal Society B: Biological Sciences 278 (1714): 2053-59. https://doi.org/10.1098/rspb.2010.2304.

Grable, John E. 2000. "Financial Risk Tolerance and Additional Factors That Affect Risk Taking in Everyday Money Matters." Journal of Business and Psychology 14 (4): 625-30. 
https://doi.org/10.1023/A:1022994314982.

Harrati, Amal. 2014. "Characterizing the Genetic Influences on Risk Aversion." Biodemography and Social Biology 60 (2): 185-98. https://doi.org/10.1080/19485565.2014.951986.

He, Qinghua, Gui Xue, Chuansheng Chen, Zhonglin Lu, Qi Dong, Xuemei Lei, Ni Ding, et al. 2010. "Serotonin Transporter Gene-Linked Polymorphic Region (5-HTTLPR) Influences Decision Making under Ambiguity and Risk in a Large Chinese Sample." Neuropharmacology 59 (6): 518-26. https://doi.org/10.1016/j.neuropharm.2010.07.008.

Heils, Armin, Andreas Teufel, Susanne Petri, Gerald Stöber, Peter Riederer, Dietmar Bengel, and K. Peter Lesch. 1996. "Allelic Variation of Human Serotonin Transporter Gene Expression." Journal of Neurochemistry 66 (6): 2621-24. https://doi.org/10.1046/j.1471-4159.1996.66062621.x.

Heinz, Andreas, David Goldman, Douglas W. Jones, Roberta Palmour, Dan Hommer, Julia G. Gorey, Kan S. Lee, Markku Linnoila, and Daniel R. Weinberger. 2000. "Genotype Influences in Vivo Dopamine Transporter Availability in Human Striatum.” Neuropsychopharmacology 22 (2): 133-39. https://doi.org/10.1016/S0893-133X(99)00099-8.

Heitland, I., R. S. Oosting, J. M.P. Baas, S. A.A. Massar, J. L. Kenemans, and K. B.E. Böcker. 2012. "Genetic Polymorphisms of the Dopamine and Serotonin Systems Modulate the Neurophysiological Response to Feedback and Risk Taking in Healthy Humans." Cognitive, Affective and Behavioral Neuroscience 12 (4): 678-91. https://doi.org/10.3758/s13415-012-0108-8.

Hirschhorn, Joel N., and Mark J. Daly. 2005. "Genome-Wide Association Studies for Common Diseases and Complex Traits.” Nature Reviews Genetics 6 (2): 95-108. https://doi.org/10.1038/nrg1521.

Jacobsen, L. K., J. K. Staley, S. S. Zoghbi, J. P. Seibyl, T. R. Kosten, R. B. Innis, and J. Gelernter. 2000. "Prediction of Dopamine Transporter Binding Availability by Genotype: A Preliminary Report." American Journal of Psychiatry 157 (10): 1700-1703. https://doi.org/10.1176/appi.ajp.157.10.1700.

Kluen, Lisa Marieke, Agorastos Agorastos, Klaus Wiedemann, and Lars Schwabe. 2017. "Cortisol Boosts Risky Decision-Making Behavior in Men but Not in Women.” Psychoneuroendocrinology 84: 181-89. https://doi.org/10.1016/j.psyneuen.2017.07.240.

Konovalov, Arkady, and Ian Krajbich. 2019. "Over a Decade of Neuroeconomics: What Have We Learned?" Organizational Research Methods 22 (1): 148-73. https://doi.org/10.1177/1094428116644502.

Kraft, Peter, Eleftheria Zeggini, and John P.A. Ioannidis. 2009. "Replication in Genome-Wide Association Studies.” Statistical Science 24 (4): 561-73. https://doi.org/10.1214/09-STS290.

Kreek, Mary Jeanne, David A. Nielsen, Eduardo R. Butelman, and K. Steven LaForge. 2005. "Genetic Influences on Impulsivity, Risk Taking, Stress Responsivity and Vulnerability to Drug Abuse and Addiction." Nature Neuroscience 8 (11): 1450-57. https://doi.org/10.1038/nn1583.

Kudielka, Brigitte M., and Stefan Wüst. 2010. "Human Models in Acute and Chronic Stress: Assessing Determinants of Individual Hypothalamuspituitaryadrenal Axis Activity and Reactivity." Stress 13 (1): 1-14. https://doi.org/10.3109/10253890902874913.

Kuhnen, Camelia M., and Joan Y. Chiao. 2009. "Genetic Determinants of Financial Risk Taking." PLoS ONE 4 (2): e4362. https://doi.org/10.1371/journal.pone.0004362.

Kuhnen, Camelia M., Gregory R. Samanez-Larkin, and Brian Knutson. 2013. "Serotonergic Genotypes, Neuroticism, and Financial Choices." PLoS ONE $8 \quad$ (1): e54632. https://doi.org/10.1371/journal.pone.0054632.

Lakshmanasamy, T. 2014. "Is Economics in Genes?" The Indian Economic Journal 61 (4): 593-625. https://doi.org/10.1177/0019466220140404.

Lancaster, T. M., D. E. Linden, and E. A. Heerey. 2012. "COMT Val158met Predicts Reward Responsiveness in Humans." Genes, Brain and Behavior 11 (8): 986-92. https://doi.org/10.1111/j.1601183X.2012.00838.x.

Lehrer, Steven F., and Weili Ding. 2017. “Are Genetic Markers of Interest for Economic Research?” IZA Journal of Labor Policy 6 (1). https://doi.org/10.1186/s40173-017-0080-6.

2019. "Can Social Scientists Use Molecular Genetic Data to Explain Individual Differences and Inform Public Policy?" In Biophysical Measurement in Experimental Social Science Research, 225-65. Elsevier Inc. https://doi.org/10.1016/b978-0-12-813092-6.00009-5.

Li, Dawei, Pak C. Sham, Michael J. Owen, and Lin He. 2006. "Meta-Analysis Shows Significant Association between Dopamine System Genes and Attention Deficit Hyperactivity Disorder (ADHD)." Human Molecular Genetics 15 (14): 2276-84. https://doi.org/10.1093/hmg/ddl152.

Linnér, Richard K., Pietro Biroli, Edward Kong, S. Fleur W. Meddens, Robbee Wedow, Mark Alan Fontana, Maël Lebreton, et al. 2019. "Genome-Wide Association Analyses of Risk Tolerance and Risky Behaviors in over 1 Million Individuals Identify Hundreds of Loci and Shared Genetic Influences." Nature Genetics 51 (2): 245-57. https://doi.org/10.1038/s41588-018-0309-3.

Loewenstein, George, Scott Rick, and Jonathan D. Cohen. 2008. "Neuroeconomics." Annual Review of Psychology 59: 647-72. https://doi.org/10.1146/annurev.psych.59.103006.093710. 
Marigorta, Urko M., Juan Antonio Rodríguez, Greg Gibson, and Arcadi Navarro. 2018. "Replicability and Prediction: Lessons and Challenges from GWAS." Trends in Genetics 34 (7): 504-17. https://doi.org/10.1016/j.tig.2018.03.005.

Martinez, Diana, Joel Gelernter, Anissa Abi-Dargham, Christopher H. Van Dyck, Lawrence Kegeles, Robert B. Innis, and Marc Laruelle. 2001. "The Variable Number of Tandem Repeats Polymorphism of the Dopamine Transporter Gene Is Not Associated with Significant Change in Dopamine Transporter Phenotype in Humans." Neuropsychopharmacology 24 (5): 553-60. https://doi.org/10.1016/S0893133X(00)00216-5.

Mata, Rui, Robin Hau, Andreas Papassotiropoulos, and Ralph Hertwig. 2012. "DAT1 Polymorphism Is Associated with Risk Taking in the Balloon Analogue Risk Task (BART)." PLoS ONE 7 (6). https://doi.org/10.1371/journal.pone.0039135.

Mata, Rui, Anika K. Josef, Gregory R. Samanez-Larkin, and Ralph Hertwig. 2011. "Age Differences in Risky Choice: A Meta-Analysis." Annals of the New York Academy of Sciences 1235 (1): 18-29. https://doi.org/10.1111/j.1749-6632.2011.06200.x.

McDermott, Rose, Dustin Tingley, Jonathan Cowden, Giovanni Frazzetto, and Dominic D.P. Johnson. 2009. "Monoamine Oxidase A Gene (MAOA) Predicts Behavioral Aggression Following Provocation." Proceedings of the National Academy of Sciences $106 \quad$ (7): 2118-23. https://doi.org/10.1073/pnas.0808376106.

Mier, D., P. Kirsch, and A. Meyer-Lindenberg. 2010. "Neural Substrates of Pleiotropic Action of Genetic Variation in COMT: A Meta-Analysis." Molecular Psychiatry 15 (9): 918-27. https://doi.org/10.1038/mp.2009.36.

Millroth, Philip, Peter Juslin, Elias Eriksson, and Thomas Agren. 2017. "Disentangling the Effects of Serotonin on Risk Perception: S-Carriers of 5-HTTLPR Are Primarily Concerned with the Magnitude of the Outcomes, Not the Uncertainty." Behavioral Neuroscience 131 (5): 421-27. https://doi.org/10.1037/bne0000209.

Mishra, Sandeep. 2014. "Decision-Making Under Risk: Integrating Perspectives From Biology, Economics, and Psychology." Personality and Social Psychology Review 18 (3): 280-307. https://doi.org/10.1177/1088868314530517.

Muda, Rafał, Mariusz Kicia, Małgorzata Michalak-Wojnowska, Michał Ginszt, Agata Filip, Piotr Gawda, and Piotr Majcher. 2018. "The Dopamine Receptor D4 Gene (DRD4) and Financial Risk-Taking: Stimulating and Instrumental Risk-Taking Propensity and Motivation to Engage in Investment Activity." Frontiers in Behavioral Neuroscience 12: 34. https://doi.org/10.3389/fnbeh.2018.00034.

Munafò, Marcus R., Binnaz Yalcin, Saffron A. Willis-Owen, and Jonathan Flint. 2008. "Association of the Dopamine D4 Receptor (DRD4) Gene and Approach-Related Personality Traits: Meta-Analysis and New Data." Biological Psychiatry 63 (2): 197-206. https://doi.org/10.1016/j.biopsych.2007.04.006.

Neukam, Philipp T., Nils B. Kroemer, Yacila I. Deza Araujo, Lydia Hellrung, Shakoor Pooseh, Marcella Rietschel, Stephanie H. Witt, Uwe Schwarzenbolz, Thomas Henle, and Michael N. Smolka. 2018. "Risk-Seeking for Losses Is Associated with 5-HTTLPR, but Not with Transient Changes in 5-HT Levels." Psychopharmacology 235 (7): 2151-65. https://doi.org/10.1007/s00213-018-4913-9.

Neve, Jan Emmanuel De, and James H. Fowler. 2014. "Credit Card Borrowing and the Monoamine Oxidase A (MAOA) Gene.” Journal of Economic Behavior and Organization 107: 428-39. https://doi.org/10.1016/j.jebo.2014.03.002.

Nicholson, Nigel, Emma Soane, Mark Fenton-O'Creevy, and Paul Willman. 2005. "Personality and DomainSpecific Risk Taking." Journal of Risk Research 8 (2): 157-76. https://doi.org/10.1080/1366987032000123856.

Nicolaou, Nicos, and Scott Shane. 2019. "Common Genetic Effects on Risk-Taking Preferences and Choices." Journal of Risk and Uncertainty 59 (3): 261-79. https://doi.org/10.1007/s11166-019-09316-2.

Roiser, Jonathan P., Benedetto De Martino, Geoffrey C.Y. Tan, Dharshan Kumaran, Ben Seymour, Nicholas W. Wood, and Raymond J. Dolan. 2009. "A Genetically Mediated Bias in Decision Making Driven by Failure of Amygdala Control." Journal of Neuroscience 29 (18): 5985-91. https://doi.org/10.1523/JNEUROSCI.0407-09.2009.

Roiser, Jonathan P., Robert D. Rogers, Lynnette J. Cook, and Barbara J. Sahakian. 2006. "The Effect of Polymorphism at the Serotonin Transporter Gene on Decision-Making, Memory and Executive Function in Ecstasy Users and Controls." Psychopharmacology 188 (2): 213-27. https://doi.org/10.1007/s00213-006-0495-z.

Sabol, Sue Z., Stella Hu, and Dean Hamer. 1998. "A Functional Polymorphism in the Monoamine Oxidase A Gene Promoter.” Human Genetics 103 (3): 273-79. https://doi.org/10.1007/s004390050816.

Sano, Akira, Keiji Kondoh, Yasuo Kakimoto, and Ikuko Kondo. 1993. "A 40-Nucleotide Repeat Polymorphism in the Human Dopamine Transporter Gene." Human Genetics 91 (4): 405-6. https://doi.org/10.1007/BF00217369. 
Sapra, Steve, Laura E. Beavin, and Paul J. Zak. 2012. “A Combination of Dopamine Genes Predicts Success by Professional Wall Street Traders.” PLoS ONE 7 (1). https://doi.org/10.1371/journal.pone.0030844.

Schultz, Wolfram. 2007. "Behavioral Dopamine Signals." Trends in Neurosciences 30 (5): $203-10$. https://doi.org/10.1016/j.tins.2007.03.007.

Senn, Theresa E., and Michael P. Carey. 2010. "Child Maltreatment and Women's Adult Sexual Risk Behavior: Childhood Sexual Abuse as a Unique Risk Factor." Child Maltreatment 15 (4): 324-35. https://doi.org/10.1177/1077559510381112.

Srivastava, Mrinalini, Gagan Deep Sharma, Achal Kumar Srivastava, and S. Senthil Kumaran. 2020. "What's in the Brain for Us: A Systematic Literature Review of Neuroeconomics and Neurofinance." Qualitative Research in Financial Markets 12 (4): 413-35. https://doi.org/10.1108/qrfm-10-2019-0127.

Stamatis, Caitlin A., Jan B. Engelmann, Christiane Ziegler, Katharina Domschke, Gregor Hasler, and Kiara R. Timpano. 2020. "A Neuroeconomic Investigation of 5-HTT/5-HT1A Gene Variation, Social Anxiety, and Risk-Taking Behavior." Anxiety, Stress and Coping 33 (2): 176-92. https://doi.org/10.1080/10615806.2020.1722597.

Stoltenberg, Scott F., Melissa K. Lehmann, Cynthia Anderson, Parthasarathi Nag, and Cheryl Anagnopoulos. 2011. "Serotonin Transporter (5-HTTLPR) Genotype and Childhood Trauma Are Associated with Individual Differences in Decision Making." Frontiers in Genetics 2 (JUNE): 1-9. https://doi.org/10.3389/fgene.2011.00033.

Stoltenberg, Scott F., and Joanna M. Vandever. 2010. "Gender Moderates the Association between 5-HTTLPR and Decision-Making under Ambiguity but Not under Risk." Neuropharmacology 58 (2): 423-28. https://doi.org/10.1016/j.neuropharm.2009.09.010.

Strawbridge, Rona J., Joey Ward, Breda Cullen, Elizabeth M. Tunbridge, Sarah Hartz, Laura Bierut, Amy Horton, et al. 2018. "Genome-Wide Analysis of Self-Reported Risk-Taking Behaviour and CrossDisorder Genetic Correlations in the UK Biobank Cohort." Translational Psychiatry 8 (1): 1-11. https://doi.org/10.1038/s41398-017-0079-1.

Sweitzer, Maggie M., Indrani Halder, Janine D. Flory, Anna E. Craig, Peter J. Gianaros, Robert E. Ferrell, and Stephen B. Manuck. 2013. "Polymorphic Variation in the Dopamine D4 Receptor Predicts Delay Discounting as a Function of Childhood Socioeconomic Status: Evidence for Differential Susceptibility." Social Cognitive and Affective Neuroscience 8 (5): 499-508. https://doi.org/10.1093/scan/nss020.

Telzer, Eva H., Andrew J. Fuligni, Matthew D. Lieberman, Michelle E. Miernicki, and Adriana Galván. 2015. "The Quality of Adolescents Peer Relationships Modulates Neural Sensitivity to Risk Taking." Social Cognitive and Affective Neuroscience 10 (3): 389-98. https://doi.org/10.1093/scan/nsu064.

Torkamani, Ali, Eric J. Topol, and Nicholas J. Schork. 2008. "Pathway Analysis of Seven Common Diseases Assessed by Genome-Wide Association.” Genomics $92 \quad$ (5): $265-72$. https://doi.org/10.1016/j.ygeno.2008.07.011.

Wang, Xiao Tian, Rui Zheng, Yan Hua Xuan, Jie Chen, and Shu Li. 2016. "Not All Risks Are Created Equal: A Twin Study and Meta-Analyses of Risk Taking across Seven Domains." Journal of Experimental Psychology: General 145 (11): 1548-60. https://doi.org/10.1037/xge0000225.

Wernerfelt, Nils, David G. Rand, Anna Dreber, Cynthia Montgomery, and Deepak K. Malhotra. 2012. "Arginine Vasopressin 1a Receptor (AVPR1a) RS3 Repeat Polymorphism Associated with Entrepreneurship." Available at SSRN 2141598. https://doi.org/10.2139/ssrn.2141598.

$\mathrm{Xu}$, Sihua, Marc Korczykowski, Senhua Zhu, and Hengyi Rao. 2013. "Assessment of Risk-Taking and Impulsive Behaviors: A Comparison between Three Tasks." Social Behavior and Personality 41 (3): 477-86. https://doi.org/10.2224/sbp.2013.41.3.477.

Zak, Paul J. 2004. "Neuroeconomics." Philosophical Transactions of the Royal Society B: Biological Sciences 359 (1451): 1737-48. https://doi.org/10.1098/rstb.2004.1544.

Zhong, Songfa, Salomon Israel, Hong Xue, Richard P. Ebstein, and Soo Hong Chew. 2009. "Monoamine Oxidase A Gene (MAOA) Associated with Attitude towards Longshot Risks." PLoS ONE 4 (12): e8516. https://doi.org/10.1371/journal.pone.0008516.

Zhong, Songfa, Salomon Israel, Hong Xue, Pak C. Sham, Richard P. Ebstein, and Soo Hong Chew. 2009. “A Neurochemical Approach to Valuation Sensitivity over Gains and Losses." Proceedings of the Royal Society B: Biological Sciences 276 (1676): 4181-88. https://doi.org/10.1098/rspb.2009.1312.

Zuckerman, Marvin, and D. Michael Kuhlman. 2000. "Personality and Risk-Taking: Common Biosocial Factors." Journal of Personality 68 (6): 999-1029. https://doi.org/10.1111/1467-6494.00124.

Zyphur, M. J., J. Narayanan, R. D. Arvey, and G. J. Alexander. 2009. "The Genetics of Economic Risk Preferences.” Journal of Behavioral Decision Making 22 (4): 367-77. https://doi.org/10.1002/bdm. 